followed: full resuscitation equipment must be available; the electrocardiograph must be continuously monitored; and a doctor must be present throughout the test and for at least 10 minutes after the end of exercise.

K M Fox

Consultant Cardiologist,

National Heart Hospital,

London W 1

${ }^{1}$ Borer JS, Brensike JF, Redwood DR, et al. Limitations of the electrocardiographic response to exercise in predicting coronary-artery disease. N Engl f Med $1975 ; 293: 367-71$.

2 Selwyn AP, Steiner R, Kivisaari A, Fox K, Forse G. Krypton-81m in the physiologic assessment of coronary arterial stenosis in man. Am $\mathcal{f}$ Cardiol $1979 ; 43: 547-53$.

${ }^{3}$ McHenry PL, Phillips JF, Knoebel SB. Correlation of computer-quantitated treadmill exercise electrocardiogram with arteriographic location of coronary artery disease. Am $\mathcal{F}$ Cardiol $1972 ; 30: 747-52$

4 Detry J-MR, Kapita BM, Cosyns J, Sottiaux B, Brasseur LA, Rousseau MF. Diagnostic value of history and maximal exercise electrocardiography in men and women suspected of coronary heart disease. Circulation $1977 ; 56: 756-61$.

${ }^{5}$ Jelliffe RW. Quantitative aspects of clinical judgment. $A m \mathcal{F}$ Med 1973;55: 431-3.

6 Diamond GA, Forrester JS. Analysis of probability as an aid in the clinical diagnosis of coronary-artery disease. $N$ Engl f Med 1979;300:1350-8.

${ }^{7}$ Redwood DR, Borer JS, Epstein SE. Whither the ST segment during exercise ? Circulation 1976;54:703-6.

${ }^{8} \mathrm{McHenry}$ PL. The actual prevalence of false positive ST-segment responses to exercise in clinically normal subjects remains undefined. Circulation 1977;55:683-5.

${ }^{9}$ Fox KM, Selwyn AP, Oakley D, Shillingford JP. Relation between the precordial projection of $S-T$ segment changes after exercise and coronary angiographic findings. Am $\mathcal{F}$ Cardiol 1979;44:1068-75.

10 Baron DW, Poole-Wilson PA, Rickards AF. Maximal 12-lead exercise testing for prediction of severity of coronary artery disease. Euro $7 \mathrm{Cardiol}$ $1980 ; 11: 259-67$.

11 Flamin MS, Mary DASG, Smith DR, Linden RJ. Prediction of severity of coronary artery disease using slope of submaximal ST segment/heart rate relationship. Cardiovasc Res 1980;14:681-91.

12 Rochmis P, Blackburn H. Exercise tests. A survey of procedures, safety and litigation experience in approximately 170000 tests. $\mathcal{F} A M A 1971 ; 217$ : 1061-6.

${ }^{13}$ Bruce RA. Progress in exercise cardiology. In: Yu PN, Goodwin JF, eds. Progress in cardiology. Vol 3. Philadelphia: Lea and Febiger, 1974:11372.

\section{The legal threat to medicine}

"The first purpose of medicine," as Mr Justice Devlin" 2 explained to the jury at the trial of Dr Bodkin Adams, "is the restoration of health. If this can no longer be achieved," he continued, "there is still much for a doctor to do, and he is entitled to do all that is proper and necessary to relieve pain and suffering, even if the measures he takes may incidentally shorten life." Dr Bodkin Adams had given large doses of morphine to a number of elderly women patients. He was convicted of several offences against various regulations concerned with dangerous drugs, cremation, and other matters associated with the deaths; but the jury found him not guilty of homicide. The case attracted considerable attention at the time and was regarded as establishing the legality of certain treatments that might incidentally shorten life. The possibility that such a pronouncement could be reversed by a higher court was regarded as academic, as the medical profession and the public considered that such a reversal would have the most serious consequences for the care of patients suffering from terminal illnesses.

Unfortunately, this is no longer the case. The Director of Public Prosecutions, ${ }^{3}$ who is required "to give advice whether on application by or on his own initiative to Government departments, clerks to justices, chief officers of police, and such other persons as he may think right in any criminal matter which appears to him to be of importance or difficulty or which for any other reason appears to him to require his intervention by way of advice and any such advice may be given at his discretion either orally or in writing," has pronounced" inter alia "that doctors who deliberately speed death could face the prospect of life imprisonment." This can mean only that he intends to challenge Lord Devlin's direction in the Bodkin Adams case. There are several important issues arising out of his pronouncement and the way in which it was made.

The first is that some unlucky doctor may shortly find himself charged with murder for giving treatment to a dying patient that incidentally hastens death. The second is that patients may find doctors more concerned about the legal indications for treatment of terminal illness than the medical motivation for treatment. Finally, we should note that the person to whom the Director of Public Prosecutions thought it right to give this advice was a reporter from the Daily Telegraph, to whom he granted an exclusive interview.

The newspaper report includes an apologia for having prosecuted Dr Arthur. ("If the prosecution had known in advance of the expert evidence to be produced by the defence it would have changed the whole course of the trial. We might not have charged murder in the first place.") It also reports the Director of Public Prosecutions's proposal that a new offence should be created specifically to deal with doctors charged with such offences. It reports his view that the law of abortion is not clear, and it contains a specific "warning" to doctors that he will "certainly have to consider whether the public interest requires a prosecution" in cases where a doctor has deliberately ended the life of a baby.

With regard to the first point, the Director of Public Prosecutions does not appear to have considered that it is the fault of our legal system that this happened. Any legal system which discourages the expert witnesses from talking to each other is bound to lead to such a situation. As for a new offence for doctors "speeding the death" of their patients, we cannot seriously accept that a doctor who eases the pain and suffering of a terminal illness should be guilty of any crime. On the Abortion Act, the Lane Committee presented three volumes of a report to Parliament in 1975 concluding that no reform of the law was necessary. And the final piece of advice assumes that anencephalics are to be kept alive at all costs, regardless of suffering and expense, until they eventually expire.

The Director of Public Prosecutions does not seem to have consulted any of the recognised representatives of the medical profession. His office has confirmed that the Daily Telegraph gave a correct report of the exclusive interview granted to the reporter. Those doctors who do not read the Daily Telegraph should therefore take note of what the Director of Public Prosecutions has said. We should also note that the Attorney General is considering referring the Arthur case to the Court of Criminal Appeal on a point of law arising out of the direction of the judge. ${ }^{5}$ Let us not also forget that in a recent case in which there were record damages of a quarter of a million pounds for severe brain damage sustained by a woman whose heart had stopped after an operation the Master of the Rolls (Lord Denning) observed that it was "a pity" that she had been resuscitated by the doctors. ${ }^{6}$

No one would claim that the law is clear on these issues. Nevertheless, until the present Director of Public Prosecutions decided to take an interest in them both the medical profession and patients felt confident that doctors following accepted medical procedures would not be prosecuted. If the Director of Public Prosecutions believes that public interest requires 
him to prosecute doctors for murder it might be as well to find out what the public thinks about it.

J D J HAVARD

Secretary,

British Medical Association

${ }^{1} \mathrm{R}$ v Adams (1957) Criminal Law Review 365.

2 Anonymous. Dr J B Adams fined on 14 charges. Br Med $\mathcal{F}$ 1957;ii:303.

3 Prosecution of Offences Regulations 1978 (SI No 135) Reg 4.

4 Daily Telegraph 1982, Feb 15:6 (col 1-3).

5 Hansard HC 10 February, col 374.

6 Lim Poh Choo v Camden \& Islington AHA [1979] 2 All ER 910 (HL)

\section{Depression after childbirth}

That "happy event," the birth of a child, is not always a source of unalloyed joy. About one in six of all births are conceived outside wedlock, and for girls under 20 the figure is seven out of 10.1 The high rate of marital breakdown gives some indication of the strains of establishing and maintaining a lasting relationship, yet the demands on the mother of her adjustment to maternity, especially for her first child, are more complex, more demanding, and subject to inflexible time restraints. Add to this the endocrine and metabolic turmoil of pregnancy and the puerperium, and it is scarcely surprising that the risk of admission to a psychiatric hospital is greater during the 12 months after childbirth than at any other time in a woman's life.

For all practical purposes, psychiatric disturbance in the puerperium is affectively based. ${ }^{2}$ Schizophrenia is largely unaffected by pregnancy, and the risk of its development in the puerperium is no higher than at any other time. Three main types of mood disturbance can be clearly identified.

The first, "baby blues," affects more than half of normal women on the third or fourth day after delivery. Weepiness is the outstanding feature, usually accompanied by despondency, lethargy, anxious feelings often related to convictions of maternal incompetence, and subjective impairment of memory and concentration. Many women welcome the contentment of the middle trimester but find the mental fogging of the puerperium distressing and are convinced that they are going mad. No treatment other than reassurance and support is required, for the condition is usually mild and always transitory.

Next is the condition best labelled postnatal depressionso long as it is not regarded as an illness which responds to antidepressants alone. Depression of this type usually develops in or after the third week of the puerperium. It varies in intensity and from day to day and is reactive to circumstances, often with a tendency to worsen as the day goes on. Anxiety, often related to the baby, irritability, and fatigue are common and impair the development of maternal competence. Variable insomnia and fluctuations in the appetite add to the difficulties of establishing the new domestic routine. Definite loss of interest in sexual relations and in her personal appearance may contribute to worsening of the woman's relationship with her partner.

Postnatal depression is usually self-limiting, with nearly two-thirds of patients recovered within a year, but the remainder have residual symptoms. Many women are left with a soured relationship with their husbands or impaired bonding with their infants. Medical recognition of this illness is in itself therapeutic, for many women and their families blame their symptoms on to physical disorders or personal inadequacy, rejecting the possibility of a recoverable emotional disorder. Reassurance, an opportunity for ventilation of her feelings, and sympathetic emotional support for the woman from family and professionals may need to be supplemented by practical help aimed at developing and reinforcing competence rather than "taking over": a washing machine, companionship, or a baby sitter may be of more value than expensive psychotherapy.

Though the emotional and social roots of postpartum depression are important, the value of symptomatic drug treatment should not be overlooked. Tricyclic antidepressants can help restore sleep and relieve persistent depression. Monoamine oxidase inhibitors demand more caution and greater skill in their use. Tranquilliser-sedatives such as diazepam or lorazepam may be of greater value, but such drugs should always be prescribed for a limited period and as part of a more comprehensive plan of treatment.

The final and most dramatic condition is one in which a few nights of insomnia may herald a florid psychosis with hallucinations, delusions, and confusion. In the past the perplexity, confusion, and common paranoid ideation have frequently led to a mistaken diagnosis of schizophrenia. The crucial distinguishing features are the acute onset and the perinatal associations. Onset is unusual within the first 48 hours, but in about $40 \%$ of cases symptoms begin within a week of delivery. The remainder are mostly spread over the next three months, with some increased risk for at least a further year. About $10 \%$ of patients with puerperal psychosis present as having a manic disorder, some with mixed depressive ideation. These cases tend to have an early onset.

The management is that of affective disorder at any time, but the acute distress and the needs of the infant may indicate an earlier recourse to electric convulsion therapy. Admission to hospital is usually required-and it should always be possible to admit the infant so that the mother may continue to care for him.

The risk of a recurrence in a subsequent pregnancy lies between $10 \%$ and $20 \%$, but a few women have a recurrence with each succeeding pregnancy. Such a course of events cannot be predicted, but three successive episodes should be accepted as grounds for advising sterilisation. The risk of a non-puerperal recurrence is that of any episode of affective disorder. The three syndromes described are clinical approximations, and in the future more knowledge will no doubt give us greater precision in diagnosis and treatment. Meanwhile we need to remember that one woman in two will get the fourday blues and be none the worse for it. One woman in 10 will have a more serious disorder, and a variety of factors may be associated with this increased risk. These include a personal or family history of depressive disorder, a major bereavement in early life, poor mothering in childhood, poor social supports, poor housing, first pregnancy, delivery by caesarean section, a recent concentration of disturbing life events, and high expressed anxiety at the end of the pregnancy. ${ }^{3} 4$

The one in 500 deliveries which is followed by a puerperal psychosis is more likely to occur in a woman with a personal or family history of affective disorder. Some have suggested that increasing anxiety towards the end of pregnancy or extreme postpartum insomnia is an important prodromal sign but generally the illness comes out of the blue.

Many psychotropic drugs are excreted in breast milk and if drug treatment is needed breast feeding should be suspended. Lactation may be maintained by expression if the treatment is expected to be short term, but severe affective disorders demand long-term treatment to prevent relapse. 